\title{
Association between serum N-terminal pro-B-type natriuretic peptide levels and characteristics of coronary atherosclerotic plaque detected by coronary computed tomography angiography
}

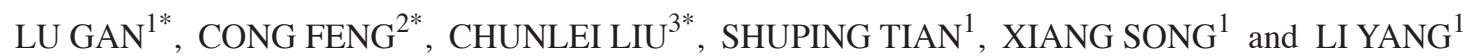 \\ Departments of ${ }^{1}$ Radiology and ${ }^{2}$ Emergency, General Hospital of the PLA, Beijing 100853; \\ ${ }^{3}$ The PLA Medical College, General Hospital of the PLA, Beijing 100853, P.R. China
}

Received May 12, 2015; Accepted January 15, 2016

DOI: $10.3892 /$ etm.2016.3371

\begin{abstract}
The aim of the present study was to explore the association between the levels of serum N-terminal pro-B-type natriuretic peptide (NT-pro BNP) and the characteristics of coronary atherosclerotic plaque detected by coronary computed tomography angiography (CCTA), in patients with unstable angina (UA). A total of 202 patients (age range, 47-82 years) were divided into the following three groups: Non-cardiac disease group (57 patients); stable angina pectoris (SAP) group (62 patients); and UA group (83 patients). There were significant differences between the serum NT-pro BNP levels among the three groups $(\mathrm{P}=0.007)$. However, in multivariant diagnoses, NT-pro BNP level was not an independent risk factor for UA. The levels of serum NT-pro BNP were observed to be positively correlated with the number of vessels involved $(\mathrm{r}=0.462 ; \mathrm{P}<0.001)$, SIS $(\mathrm{r}=0.475 ; \mathrm{P}<0.001)$, segment-stenosis score $(\mathrm{r}=0.453 ; \mathrm{P}<0.001)$, coronary calcification score $(\mathrm{r}=0.412 ; \mathrm{P}=0.001)$, number of obstructive diseases $(\mathrm{r}=0.346 ; \mathrm{P}<0.001)$, and the number of segments with non-calcified plaque $(\mathrm{r}=0.235 ; \mathrm{P}=0.017)$, mixed plaque $(\mathrm{r}=0.234 ; \mathrm{P}=0.017)$ and calcified plaque $(\mathrm{r}=0.431 ; \mathrm{P}<0.001)$. The levels of serum NT-pro BNP were significantly higher in patients with UA and left main-left anterior descending (LM-LAD) disease, compared with UA patients without LM-LAD disease $(\mathrm{P}<0.001)$. In addition, serum NT-pro BNP was significantly higher in patients with obstructive disease and UA than in those without obstructive disease $(\mathrm{P}<0.001)$. The area under the curve of $\log (\mathrm{NT}$-pro BNP $)$ was 0.656 ( $\mathrm{P}=0.006$; optimal cut-off value, 1.74 ; sensitivity,
\end{abstract}

Correspondence to: Dr Li Yang, Department of Radiology, General Hospital of the PLA, 28 Fuxing Road, Beijing 100853, P.R. China

E-mail: 13805366900@126.com

* Contributed equally

Key words: N-terminal pro-B-type natriuretic peptide, coronary atherosclerotic plaque, unstable angina
77.6\%; specificity, 51.9\%). In conclusion, the levels of serum NT-pro BNP are associated with the burden and severity of coronary artery atherosclerotic disease in patients with UA, and may be helpful in risk stratification of patients with UA.

\section{Introduction}

B-type natriuretic peptide (BNP) is predominantly secreted by ventricular cardiomyocytes in patients with chronic cardiac disease (1). It serves a key role in the regulation of circulation and the balance of water and electrolytes (2), and it is closely associated with the systolic and diastolic functions of myocardial cells (3). At present, BNP is considered to be an effective index of evaluation for myocardial function (4). However, the levels of serum N-terminal pro-BNP (NT-pro BNP) are closely associated with BNP, and NT-pro BNP is stable enough to be detected using laboratory tests (5).

Coronary heart disease (CAD) is one of the most frequent causes of morbidity and mortality worldwide, and it is well known that the predominant factor of CAD is atherosclerosis, which is a chronic and progressive inflammatory disease (6). The pathogenesis of acute coronary syndrome (ACS) includes the rupture or erosion of a vulnerable plaque, which is characterized by infiltration of inflammatory cells, a large necrotic core and a thin fibrous cap (7). It is believed that the earlier the detection of UA, the better chances exist regarding treatment and prognosis.

Numerous studies have demonstrated that the levels of serum NT-pro BNP are associated with the severity and prognosis of coronary atherosclerotic disease (8-11). At present, computed tomography angiography (CTA) is the optimal non-invasive method for assessing the burden and components of coronary plaques (12). This technique is highly consistent with optical coherence tomography (OCT) and intravascular ultrasound (IVUS), which are widely considered as the 'gold standard' methods for assessing plaque characteristics (13). Currently, coronary CTA (CCTA) is widely used to evaluate the risk and stability of coronary atherosclerotic plaques in patients with unstable angina (UA) (14-16).

Zhou et al (17) oserved that the concentration of BNP was significantly higher in patients with carotid plaque compared with those without carotid plaque, and the presence of the 
plaque positively correlated with carotid intima-media thickness (17). Hong et al (18) demonstrated that patients with high NT-pro-BNP expression levels had more vulnerable plaque components (more non-calcified-containing lesions and a higher frequency of thin-cap fibroatheroma, as assessed by virtual histology-IVUS). In addition, Peng et al (19) observed that patients with essential hypertension and moderate and elevated BNP had significantly higher left ventricular mass index, intima-media thickness, coronary calcification score (CCS) and microalbuminuria levels compared with those with normal BNP expression levels, as assessed by ultrasound and coronary CT examinations (19). The above studies were investigated the associations between carotid atherosclerosis plaque burden, coronary artery plaque calcification score and BNP/NT-pro BNP. Altintas et al (20) demonstrated that serum NT-pro BNP expression level was associated with total plaque burden and calcification volume in patients with stable chest pain (20). However, currently there are no studies investigating the association between serum BNP/NT-pro BNP expression level and characteristics of coronary artery plaque in patients with ACS, in particular with regards to the burden and composition of plaques, as assessed by CT.

The present study explores the association between the levels of serum NT-pro BNP and the characteristics of atherosclerotic plaques, as determined by CCTA.

\section{Materials and methods}

Subjects. A total of 202 patients (age range, 47-82 years; mean age, 74.5 years; male to female ratio, 1.8:1) were recruited for the present study between January 2013 and 2014 in the Chinese General Hospital of the PLA (Beijing, China). Informed patient consent was obtained prior to the collection of blood samples for the detection of serum NT-pro BNP. The study was approved by the Institutional Ethics Committee for human subjects, and was approved by the ethics committee of the Chinese General Hospital of the PLA. Written informed consent was obtained from the patients.

Inclusion criteria. Patients with stable angina pectoris (SAP) and UA, diagnosed according to the AHA/ACC Guideline for the Management of Patients with Non-ST-Elevation Acute Coronary Syndromes (21), were included in the study.

Exclusion criteria. Patients were excluded from the study if they matched any of the following criteria: Acute myocardial infarction, cardiomyopathy, valvular disease, cardiac dysfunction, coronary revascularization (including percutaneous coronary intervention, stenting and coronary artery bypass grafting), renal insufficiency, iodine allergy, poor tolerance to CCTA examination, pregnancy and minors.

Study design. All subjects underwent CCTA examination and blood samples were taken for the detection of serum NT-pro BNP within 12-48 $\mathrm{h}$ following the onset of illness or admission to hospital. Blood samples were drawn prior to the CTTA examination and stored at $-80^{\circ} \mathrm{C}$ until assays were performed. Arterial hypertension was defined by the use of antihypertensive drugs prescribed by a physician, or reported systolic blood pressures $>140 \mathrm{mmHg}$. Hyperlipidemia was defined by
$200 \mathrm{mg} / \mathrm{dl}$ total cholesterol, or the use of statins to treat hyperlipidemia at present or in the past. Patients with UA $(n=83)$ were analyzed as the experimental group, and patients with SAP $(n=62)$ and non-cardiac diseases $(n=57)$ were treated as control groups.

Scan protocol and image reconstruction. Scans were performed according to SCCT guidelines (22) for the performance of CCTA with a multidetector computed tomography (CT) scanner (256 iCT; Philips Healthcare, Andover, MA, USA). Helical scan data was obtained using retrospective or prospective electrocardiographic gating. Prior to performing the CCTA, 50-60 ml iodinated contrast media $(370 \mathrm{mg} \mathrm{I} / \mathrm{ml}$, Bayer AG, Leverkusen, Germany) was injected followed by a $35-40 \mathrm{ml}$ saline flush $(4.5-5 \mathrm{ml} / \mathrm{s})$. The threshold tract trigger mode of the region of interest was adopted (23). Images were reconstructed at 40,45 and $78 \%$ of the cardiac cycle, consistently and immediately following the completion of a scan. The optimal phase reconstruction was assessed by comparison with the phase that had the least amount of coronary artery motion. The images were evaluated using transaxial two-dimensional image stacks (raw data), multiplanar reformations, maximum intensity projections, curved multiplanar reformations and volume-rendering technique reconstructions. If a coronary artery segment was uninterpretable (characterized by artifacts, such as motion, beam hardening, metal or calcium-related partial volume averaging, and adequacy of over contrast concentration or opacification) (24), it was not included in the analysis. IntelliSpace Portal 6 (Philips Healthcare, Andover, MA, USA) was used to analyze the images.

Image analysis and definition of atherosclerotic plaque in the coronary artery. In each coronary artery segment, coronary atherosclerosis was defined as the presence of tissue structures $>1 \mathrm{~mm}^{2}$ that existed within the coronary artery lumen or adjacent to the coronary artery lumen that could be discriminated from surrounding pericardial tissues, epicardial fat or the vessel lumen itself. Coronary artery segments were identified according to the 15-Segment American Heart Association model (25). Calcification of plaques was graded according to the following criteria: Non-calcified plaque $(<20 \%$ calcification; mean CT, $\leq 150 \mathrm{HU}$ ); mixed plaque (20-80\% calcification); and calcified plaque (>80\% calcification; mean CT, $>130 \mathrm{HU}$ ).

Evaluation indicators. Images were analyzed for plaque and individual aspects. Evaluation indicators for individual aspects included left main-left anterior descending (LM-LAD) disease and obstructive diseases (stenosis degree of the coronary artery of $\geq 50 \%$ ), and the number of segments of calcified plaque, non-calcified plaque and mixed plaque. Coronary calcium scoring computer programs typically identify pixels that exceed $130 \mathrm{HU}$ as a level corresponding to calcium on a non-contrast study Plaques were evaluated according to the following criteria: CCS (Agaston score) (26); segment-involvement score (SIS; range 0-15); segment-stenosis score [SSS; range, 0-3; $0=$ normal, $1=$ mild $(<50 \%), 2=$ moderate $(\geq 50-70 \%)$, $3=$ severe $(\geq 70 \%)$; obstructive disease $=\geq 2$ points]; and the number of vessels (range, 0-4). Degrees of luminal stenosis were calculated on the basis of the vessel diameter. SSS ranged between 0 and 45 points. 
Blind method. Each image was analyzed by two radiologists with experience of interpreting several thousands of CCTA scans. The radiologists had no knowledge of the clinical diagnosis and laboratory results of the patients.

Laboratory examination. Fasting blood samples $(4.0 \mathrm{ml})$ were collected using vacuum tubes and serum was separated $30 \mathrm{~min}$ following sample extraction by centrifugation at $14,000 \mathrm{x} \mathrm{g}$ for $20 \mathrm{~min}$ at room temperature. An automatic biochemical analyzer (7600DDP; Hitachi, Ltd., Tokyo, Japan) was used to detect levels of serum NT-pro BNP.

Statistical analysis. Patient demographic characteristics were presented as the mean \pm standard deviation or as medians (interquartile ranges) for continuous variables, and as proportions (percentages) for categorical variables. The levels of serum NT-pro BNP were normally distributed with logarithmic transformation. Non-parametric Mann-Whitney U or Kruskal-Wallis tests were used to compare continuous variables, and the Pearson's $\chi^{2}$ test was used to evaluate differences in frequencies. Correlations between variables were analyzed using a linear and binary logistic regression model. Receiver-operating characteristic (ROC) curve analysis was used to evaluate the authenticity and reliability of the study and estimate the optimal threshold (cut-off value obtained from ROC). Statistical comparisons were performed using SPSS version 19.0 (SPSS, Inc., Chicago, IL, USA). P<0.05 was considered to indicate a statistically significant difference.

\section{Results}

Baseline information and levels of serum NT-pro BNP. There were no statistically significant differences between patient parameters, including heart rate and blood pressure, among the three groups (UA, SAP and non-cardiac disease groups; Tables I and II). The analysis of serum NT-pro BNP levels among the three groups is presented in Table III. Logarithmic values of NT-pro BNP serum levels are as follows: Non-cardiac disease group $(1.57 \pm 0.57 ; \mathrm{n}=57 ; 95 \% \mathrm{CI}, 1.53-1.98)$; SAP group $(1.93 \pm 0.50 ; \mathrm{n}=62 ; 95 \% \mathrm{CI}, 1.73-2.12)$; and UA group $(2.16 \pm 0.53 ; \mathrm{n}=83 ; 95 \% \mathrm{CI}, 2.00-2.31)$. There were statistically significant differences in the $\log (\mathrm{NT}$-pro BNP) values between the three groups (Table III).

Atherosclerotic plaque characteristics assessed by CCTA. The data from the analysis of the atherosclerotic plaque CCTA characteristics among the three groups is presented in Table IV. There was no correlation between the levels of serum NT-pro BNP and the characteristics of atherosclerotic plaques, detected by CCTA, between the SAP and control group.

Association between serum NT-pro BNP expression levels and characteristics of plaques in patients with UA. The correlation analysis between the levels of serum NT-pro BNP and characteristics of atherosclerotic plaques detected by CCTA in patients with UA is presented in Table V. In the UA group, $\log$ (NT-pro BNP) had various degrees of linear correlation with the number of vessels $(r=0.462, P<0.001)$, SIS $(r=0.475$, $\mathrm{P}<0.001)$, SSS $(\mathrm{r}=0.453, \mathrm{P}<0.001), \mathrm{CCS}(\mathrm{r}=0.412, \mathrm{P}<0.001)$, obstructive disease $(r=0.346, P<0.001)$ and the number of
Table I. Patient information.

\begin{tabular}{lccccc}
\hline Parameter & NC & SAP & UA & F-value & P-value \\
\hline Age & $56.8 \pm 11$ & $60.4 \pm 9.6$ & $62.7 \pm 11$ & 2.724 & 0.070 \\
HR & $71.6 \pm 12$ & $73.5 \pm 11$ & $75.5 \pm 15$ & 0.786 & 0.458 \\
SBP & $135 \pm 19$ & $136 \pm 16$ & $138 \pm 23$ & 0.300 & 0.741 \\
DBP & $80.0 \pm 11$ & $77.0 \pm 8.0$ & $77.0 \pm 11$ & 0.614 & 0.543 \\
BMI & $26.0 \pm 2.8$ & $26.7 \pm 5.0$ & $25.7 \pm 3.2$ & 0.568 & 0.568 \\
\hline
\end{tabular}

The non-cardiac disease group served as the control. NC, non-cardiac group; SAP, stable angina pectoris group; UA, unstable angina group; $\mathrm{HR}$, heart rate; SBP, systolic blood pressure; DBP, diastolic blood pressure; BMI, body mass index.

Table II. Patient information $(n=202)$.

\begin{tabular}{lcc}
\hline Parameter & $\chi^{2}$ & P-value \\
\hline Gender (male) & 4.626 & 0.099 \\
Hypertension & 1.001 & 0.606 \\
Diabetes mellitus & 0.017 & 0.991 \\
Dyslipidemia & 0.588 & 0.745 \\
Family history & 0.115 & 0.944 \\
Smoking & 0.950 & 0.622 \\
\hline
\end{tabular}

Table III. Levels of NT-pro BNP in the control (non-cardiac disease), SAP and UA groups.

\begin{tabular}{lcccc}
\hline Group & N & $\log ($ NT-pro BNP) & $95 \%$ CI & P-value \\
\hline NC & 57 & $1.57 \pm 0.57$ & $1.53-1.98$ & $0.007^{\mathrm{a}}$ \\
SAP & 62 & $1.93 \pm 0.50^{\mathrm{b}}$ & $1.73-2.12$ & \\
UA & 83 & $2.16 \pm 0.53^{\mathrm{c}, \mathrm{d}}$ & $2.00-2.31$ & \\
\hline
\end{tabular}

${ }^{a}$ Multivariate analysis of all groups; ${ }^{\mathrm{S}} \mathrm{SAP}$, vs. the control group, $\mathrm{P}=0.363$; ' $\mathrm{UA}$, vs. the control group, $\mathrm{P}=0.004$; ${ }^{\mathrm{U}} \mathrm{UA}$, vs. the SAP group, $\mathrm{P}=0.14$. NT-pro $\mathrm{BNP}, \mathrm{N}$-terminal pro-B-type natriuretic peptide; $\mathrm{CI}$, confidence interval; $\mathrm{NC}$, non-cardiac; SAP, stable angina pectoris; UA, unstable angina.

segments with non-calcified plaque $(\mathrm{r}=0.235, \mathrm{P}=0.017)$, mixed plaque $(\mathrm{r}=0.234, \mathrm{P}=0.017)$ and calcified plaque $(\mathrm{r}=0.431$, $\mathrm{P}<0.001)$. However, following the adjustment of various conventional risk factors, $\log$ (NT-pro BNP) was not determined to be an independent risk factor of UA (Table VI).

Association between serum NT-pro BNP expression levels and $L M-L A D$ disease in patients with UA. There were statistically significant differences between the prevalence of LM-LAD disease among the three groups. LM-LAD was most common in patients with UA (Fig. $1 ; \chi^{2}=21.444, \mathrm{P}<0.001$ ) and the levels of serum NT-pro BNP were significantly higher in patients with UA and LM-LAD disease compared with UA patients without LM-LAD disease $(2.12 \pm 0.52$ vs. $1.64 \pm 0.48 ; \mathrm{P}<0.001$; Table VII). 
Table IV. Univariant and multivariant analysis of the association between serum NT-pro BNP levels and US.

\begin{tabular}{lcccc}
\hline Parameter & NC & SAP & UA & P-value \\
\hline Vessels & $1.26 \pm 1.46$ & $2.26 \pm 1.13^{\mathrm{a}}$ & $2.13 \pm 1.27^{\mathrm{b}, \mathrm{c}}$ & 0.008 \\
SIS & $1.96 \pm 2.67$ & $2.89 \pm 2.01^{\mathrm{d}}$ & $3.56 \pm 3.22^{\mathrm{e}, \mathrm{f}}$ & 0.019 \\
SSS & $3.04 \pm 0.99$ & $3.78 \pm 3.87$ & $5.33 \pm 5.72$ & 0.066 \\
NCP & $1.33 \pm 2.62$ & $1.72 \pm 1.34$ & $2.53 \pm 2.34$ & 0.458 \\
MP & $0.07 \pm 0.27$ & $0.56 \pm 0.90^{\mathrm{g}}$ & $0.92 \pm 0.23^{\mathrm{h}, \mathrm{i}}$ & 0.009 \\
CP & $0.89 \pm 1.69$ & $1.15 \pm 1.46$ & $2.33 \pm 3.97$ & 0.108 \\
CCS & $27.8 \pm 12.6$ & $148.3 \pm 102.4$ & $287.5 \pm 259.2$ & 0.101 \\
\hline
\end{tabular}

${ }^{\mathrm{a}} \mathrm{SAP}$, vs. the control group, $\mathrm{P}=0.01$; ${ }^{\mathrm{b}} \mathrm{UA}$, vs. the control group, $\mathrm{P}=0.012$; ${ }^{\mathrm{C}} \mathrm{UA}$, vs. the SAP group, $\mathrm{P}=0.88$; ${ }^{\mathrm{d}} \mathrm{SAP}$, vs. the control group, $\mathrm{P}=0.365$; ${ }^{\mathrm{e}} \mathrm{UA}$, vs. the control group, $\mathrm{P}=0.037$; ${ }^{\mathrm{f}} \mathrm{UA}$, vs. the SAP group, $\mathrm{P}=0.52$; ${ }^{\mathrm{g}} \mathrm{SAP}$, vs. the control group, $\mathrm{P}=0.014$; ${ }^{\mathrm{h}} \mathrm{UA}$, vs. the control group, $\mathrm{P}=0.002 ;{ }^{1} \mathrm{UA}$, vs. the $\mathrm{SAP}$ group, $\mathrm{P}=0.523$. $\mathrm{NC}$, non-cardiac group; SAP, stable angina pectoris group; UA, unstable angina group; SIS, segment-involvement score; SSS, segment-stenosis score; NCP, non-calcified plaque; MP, mixed plaque; $\mathrm{CP}$, calcified plaque; CCS, coronary calcification score.

Table V. Correlation between N-terminal pro-B-type natriuretic peptide levels and coronary computed tomography angiography characteristics in patients with unstable angina.

\begin{tabular}{lcr}
\hline Parameter & R-value & P-value \\
\hline Vessel number & 0.462 & $<0.001$ \\
SIS & 0.475 & $<0.001$ \\
SSS & 0.453 & $<0.001$ \\
OD & 0.346 & $<0.001$ \\
NCP & 0.235 & 0.017 \\
MP & 0.234 & 0.017 \\
CP & 0.431 & $<0.001$ \\
CCS & 0.412 & 0.001 \\
\hline
\end{tabular}

SIS, segment-involvement score; SSS, segment-stenosis score, OD, obstructive disease; NCP, non-calcified plaque; MP, mixed plaque; $\mathrm{CP}$, calcified plaque; $\mathrm{CCS}$, coronary calcification score.

Table VI. Analysis of $\log (\mathrm{N}$-terminal pro-B-type natriuretic peptide).

\begin{tabular}{lcccc}
\hline Analysis & P-value & OR & 95\% CI UL & 95\% CI LL \\
\hline Univariable & 0.008 & 2.892 & 1.326 & 6.309 \\
Multivariable & 0.053 & 2.723 & 0.985 & 7.526
\end{tabular}

OR, odds ratio; CI, confidence interval; UL, upper limit; LL, lower limit.

Association between serum NT-pro BNP expression levels and obstructive disease in patients with UA. There were statistically significant differences between the number of identified

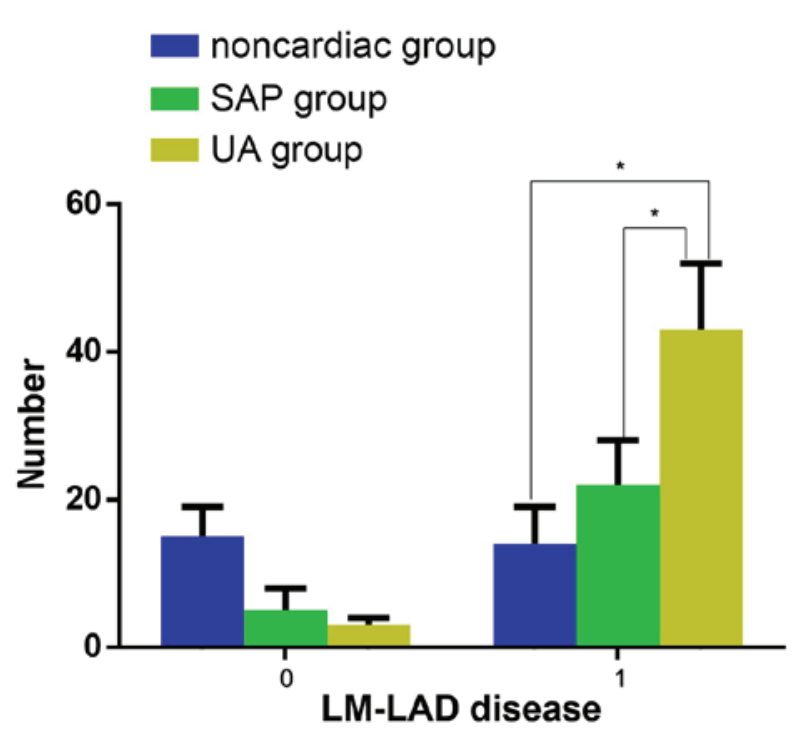

Figure 1. Presence of LM-LAD disease. There were significant differences between the prevalence of LM-LAD disease among the non-cardiac, SAP and UA groups. LM-LAD disease was the most common in patients with UA. " $\mathrm{P}<0.05$. Blue, non-cardiac disease group; green, SAP group; yellow, UA group. LM-LAD, left main-left anterior descending; SAP, stable angina pectoris; UA, unstable angina.

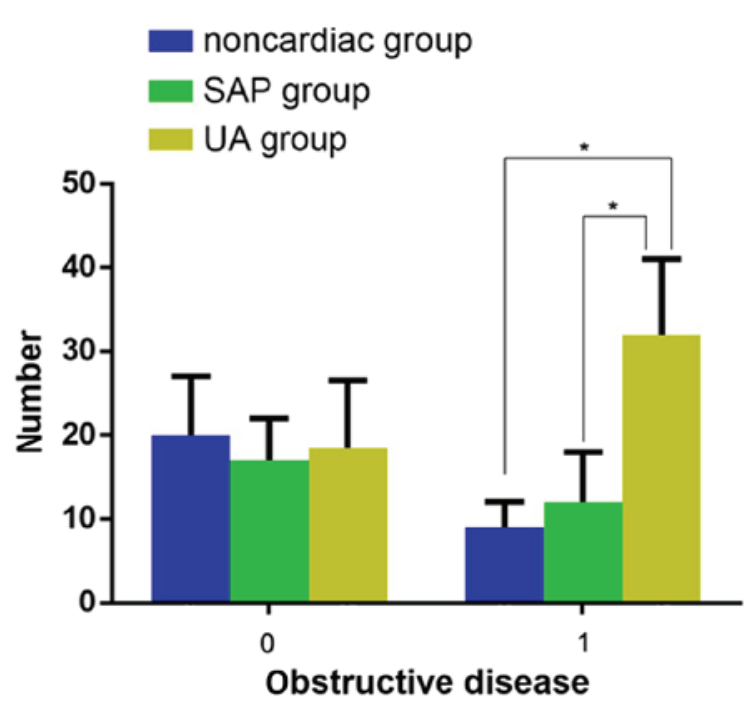

Figure 2. Presence of obstructive disease. There were significant differences between the prevalence of obstructive disease among the non-cardiac, SAP and UA groups. Obstructive disease was the most severe in patients with UA. ${ }^{*} \mathrm{P}<0.05$. Blue, non-cardiac disease group; green, SAP group; yellow, UA group. SAP, stable angina pectoris; UA, unstable angina.

obstructive diseases among the three groups, and patients in the UA group experienced the most severe obstructive disease (Fig. $2 ; \chi^{2}=10.113, \mathrm{P}=0.006$ ). In addition, in patients with UA the levels of serum N-pro BNP in those with obstructive diseases was significantly higher compared with those without obstructive diseases (Table VIII; 1.78 \pm 0.49 , vs. 2.22 \pm 0.54 ; $\mathrm{P}<0.001$ ); however, the levels of serum N-pro BNP did not increase when the number of obstructive vessels increased ( $\mathrm{P}=0.400$; Table IX).

ROC of serum NT-pro BNP expression levels and indexes of CCTA plaque characteristics to identify patients with UA. 
Table VII. Levels of serum N-terminal pro-B-type natriuretic peptide in LM-LAD disease in patients with unstable angina.

\begin{tabular}{lr}
\hline Group & $\log (\mathrm{N}-$ pro BNP $)(\mathrm{pg} / \mathrm{ml})$ \\
\hline With LM-LAD & $2.12 \pm 0.52^{\mathrm{a}}$ \\
Without LM-LAD & $1.64 \pm 0.48$ \\
\hline
\end{tabular}

a'With LM-LAD, vs. without LM-LAD, P $<0.001$. LM-LAD, left main-left anterior descending.

Table VIII. Level of serum $\log ($ NT-pro BNP) in patients with obstructive disease and unstable angina.

Disease status

Non-obstructive

Log(NT-pro BNP)

Obstructive

$1.78 \pm 0.49^{\mathrm{a}}$

$2.22 \pm 0.54$

${ }^{\mathrm{a} N o n-o b s t r u c t i v e ~ d i s e a s e, ~ v s . ~ o b s t r u c t i v e ~ d i s e a s e, ~} \mathrm{P}<0.001$. NT-pro BNP, N-terminal pro-B-type natriuretic peptide.

Table IX. Level of serum NT-pro BNP $(\mathrm{pg} / \mathrm{ml})$ in patients in the unstable angina group with OD.

\begin{tabular}{lcccc}
\hline OD & N & Log(NT-pro BNP) & $95 \%$ CI & P-value \\
\hline Non-OD & 57 & $1.78 \pm 0.49$ & $1.65-1.92$ & $<0.001^{\mathrm{a}}$ \\
1 OD & 102 & $2.09 \pm 0.51^{\mathrm{b}}$ & $1.89-2.38$ & \\
$\geq 2$ OD & 43 & $2.12 \pm 0.56^{\mathrm{c}, \mathrm{d}}$ & $2.07-2.53$ & \\
\hline
\end{tabular}

${ }^{\mathrm{a}}$ Multivariate analysis of all groups; ${ }^{\mathrm{b}} 1$ obstructive vessel, vs. non-obstructive vessel, $\mathrm{P}<0.001 ;{ }^{\mathrm{c}} \geq 2$ obstructive vessels, vs. non-obstructive vessel, $\mathrm{P}=0.022 ; \mathrm{d} \geq 2$ obstructive vessels, vs. 1 obstructive vessel, $\mathrm{P}=0.400$. NT-pro $\mathrm{BNP}, \mathrm{N}$-terminal pro-B-type natriuretic peptide; OD, obstructive disease; $\mathrm{CI}$, confidence interval.

Using the SAP and non-cardiac disease groups as control groups, ROC curves were plotted (Fig. 3). In patients with UA, the area under the curve (AUC) was 0.656 (95\% CI, 0.55-0.762; $\mathrm{P}=0.006$ ) and the optimal cut-off value was 1.74 (Fig. 3). The sensitivity, specificity, LR (likely ratio), Youden index, OR (odds ratio), CI and Kappa values of NT-pro BNP in patients with UA are presented in Table X. In addition, the AUC of vessels, SIS, SSS and the number of segments with calcified plaque, non-calcified plaque and mixed plaque are presented in Table XI.

\section{Discussion}

In the present study, the results demonstrated that the levels of serum NT-pro BNP have a positive correlation with atherosclerotic plaque, and specifically calcified plaque. It has been demonstrated that the pathogenesis of UA involves the rupture or erosion of vulnerable plaques and secondary thrombosis (27), leading to an acute occlusion of coronary
Table X. N-pro BNP parameters of patients in the unstable angina group.

\begin{tabular}{lc}
\hline Parameter & NT-pro BNP \\
\hline Sensitivity & $77.6 \%$ \\
Specificity & $51.9 \%$ \\
Likely positive ratio & 1.61 \\
Likely negative ration & 0.43 \\
Youden index & 0.295 \\
Odds ratio & 3.841 \\
95\% Confidence interval & $2.077-7.102$
\end{tabular}

Table XI. Receiver operating characteristic analysis of vessels, SIS, SSS, and the number of segments with NCP, MP and CP.

\begin{tabular}{lcc}
\hline Parameter & AUC & P-value \\
\hline Number of vessels & 0.573 & 0.204 \\
SIS & 0.592 & 0.109 \\
SSS & 0.608 & 0.060 \\
NCP & 0.599 & 0.082 \\
MP & 0.591 & 0.112 \\
CP & 0.513 & 0.825 \\
\hline
\end{tabular}

AUC, area under of the curve; Vessel, number of involved vessels; SIS, segment-involved score; SSS, segment-stenosis score; NCP, non-calcified plaque; MP, mixed plaque; $\mathrm{CP}$, calcified plaque.

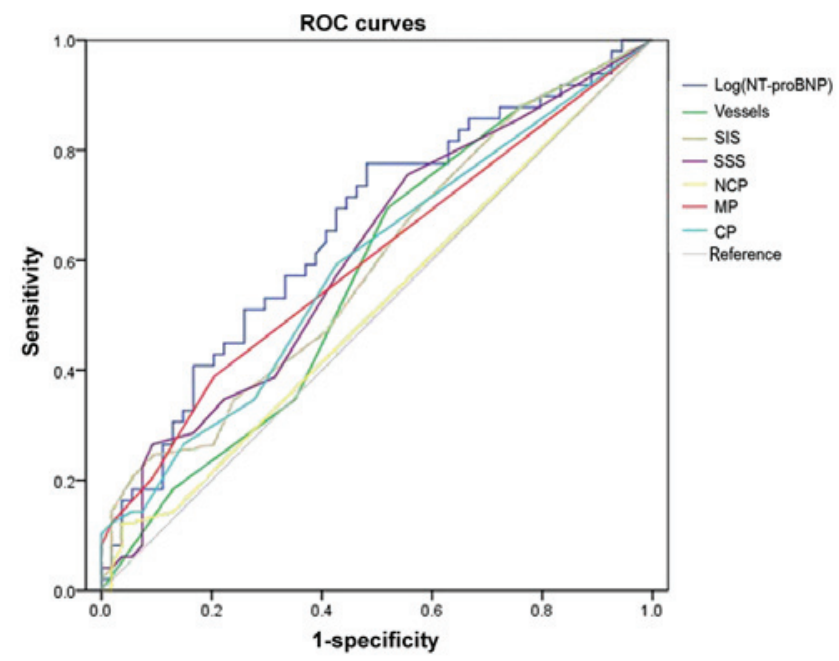

Figure 3. ROC curve of the unstable angina and control (stable angina pectoris and non-cardiac disease) group. For patients with unstable angina, the area under the curve is $0.656 ; 95 \%$ confidence interval, $0.55-0.762 ; \mathrm{P}=0.006$ (ROC analysis); optimal cut-off value, 1.74. ROC, receiver operating characteristics; SIS, segment-involvement score; SSS, segment-stenosis score; $\mathrm{NCP}$, non-calcified plaque; MP, mixed plaque; $\mathrm{CP}$, calcified plaque.

arteries. Acute myocardial ischemia is categorized under the Major Adverse Cardiovascular Events (MACE), which also includes UA, acute myocardial infarction (AMI) and sudden cardiac death. Numerous studies have demonstrated that there 
is cross-talk between the endocrine and contractile functions of the heart, which acts as a pump as well as a multifunctional and interactive organ (28-31).

Changes in ventricular wall tension, stimulation of myocardial cells and myocardial ischemia can immediately induce the secretion of BNP $(32,33)$. When ventricular cardiomyocytes are stimulated, pre-pro BNP is released and cleaved into active BNP and inactive NT-pro BNP (34). Currently, BNP and NT-pro BNP are primarily used for the screening of heart disease, identifying the risk of congestive heart failure, detecting dysfunction of the left ventricle, differentially diagnosing dyspnea, and diagnosing acute and chronic heart failure $(8,9,11)$.

Research into acute coronary syndrome (ACS) and AMI has demonstrated that levels of serum NT-pro BNP are closely associated with the severity and prognosis of coronary artery disease (35). Invasive examination, coronary angiography, optical OCT and intravascular ultra-sound IVUS are used in a large number of these studies (18,36-38). However, in the present study it was observed that the majority of patients with ACS preferred examination with noninvasive CCTA rather than the invasive methods discussed above. Although there are limitations to the detection of lipid necrotic cores and fiber caps using CCTA, with the development of scanning and post-processing techniques, CCTA may transform into a preferred option compared with OCT and IVUS, which are currently considered the 'gold standard' for detecting vulnerable plaques $(13,15,39,40)$. In addition, the rupture or erosion of vulnerable plaques may increase the level of serum BNP and NT-pro BNP in a short period of time $(5,41,42)$. Therefore, using CCTA in patients with UA to detect changes in serum NT-pro BNP levels and the characteristics of atherosclerotic plaques may have important clinical significance.

A previous study of IVUS demonstrated that the levels of serum NT-pro BNP are significantly associated with vulnerable plaques which have relatively large necrotic cores or thin fibrous caps (43). In the present study, high levels of serum NT-pro BNP were associated with a high volume of calcified plaque. In particular, serum NT-pro BNP levels were associated with the composition of atherosclerotic and calcified plaque (correlation coefficient, 0.431), as compared with non-calcified and mixed plaque that were not associated with serum NT-pro BNP (OR=0.235 and 0.234 respectively). To the best of our knowledge, these findings have not been previously reported.

The formation of atherosclerotic plaque is a complex process comprised of three stages: The formation of lipid plaques, fibrous plaques and complex lesions $(44,45)$. Plaques in various stages present different characteristics on a CCTA, including low-density non calcified plaque, high-density non calcified plaque, mixed plaque and calcified plaque (46) Considering the limitations of detecting low-density and high-density non-calcified plaques using CCTA (11), these two types of plaque were considered to be non-calcified plaque in the present study.

Salama et al (47) observed that calcified plaques were commonly found in mid-to-late stage of atherosclerosis. In these stages, the severity and extent of the disease is more serious than in the early stages. In addition, the formation of atherosclerotic plaque was a non-linear process, in which stable and unstable plaques coexisted and calcified, and non-calcified and mixed plaques could be observed in a patient at any time. Non-calcified and mixed plaques can be frequently unstable and vulnerable to rupture or erosion (48). However, calcified plaques often coexist with more severe luminal stenosis in mid- and late-stages of disease and are associated with inflammatory processes $(49,50)$. Once the rupture or erosion of vulnerable plaque occurs, the degree of myocardial infarction can be more serious than that of early stage disease in which only non-calcified plaques exist. When plaques rupture or erode, the level of serum NT-pro BNP increases (51-53).

The results in the present study suggested that the increase of serum NT-pro BNP levels in patients with UA is a result of the rupture or erosion of vulnerable plaques, and is relative to the extent of lesion, degree of luminal stenosis and the number of segments that are affected by calcified plaques. The present study also demonstrated that the levels of serum NT-pro BNP in patients with UA are significantly higher, as compared with those in control groups, and that they are associated with the severity of the lesion, the degree of luminal stenosis and LM-LAD disease, and the number of segments affected by calcified plaques.

The results of the present study were concordant with those of a previous study conducted by Palazzuoli et al (54), who demonstrated that the level of NT-pro BNP is positively correlated with SIS, SSS and the number of involved vessels. Palazzuoli et al (54) observed that the level of NT-pro BNP is higher in patients with $>3$ vessels implicated. Sadanandan et al (55) observed that the levels of serum NT-pro BNP increased in the coronary angiography when the degree of luminal stenosis was $>76 \%$ or LM-LAD was present, and Radwan et al (41) reported similar findings when using IVUS. It can therefore be speculated that high degree stenosis and extensive lesions may weaken the compensatory abilities of the myocardium, exacerbate myocardial ischemia and provoke the ongoing release of NT-pro BNP and BNP. However, the same correlation in patients with SAP was not observed in the current study. Furthermore, the results from the present study were not concordant with those reported by Weber et al (56), although that particular study did not mention the incorporation of a time frame in which they extracted blood samples, which is a critical stage in testing for serum NT-pro BNP. However, an insufficient sample size in the present study may have led to inaccurate results.

In the current study, the AUC of serum NT-pro BNP levels in patients with UA was 0.656 , which is marginally higher than that of non-ST-elevated myocardial infarction, but lower than that of ST-elevated myocardial infarction (47). The serum NT-pro BNM optimal cut-off value was $55 \mathrm{pg} / \mathrm{ml}$, sensitivity was $77.6 \%$ and specificity was $51.9 \%$. There are large discrepancies between the results of the present study and those reported by Liu et al (57), which may be due to the use of different patient types; Liu et al (57) used patients with ACS. The levels of serum NT-pro BNP were higher in patients with non-ST-elevated myocardial infarction compared with patients with UA. In addition, Liu et al (57) described blood samples being drawn immediately following admission to hospital, not at $\mathrm{T}_{\max }$, which would lead to inaccurate results; it is difficult to identify the Tmax in patients with non-cardiac disease (58), therefore, blood samples were taken $12-48 \mathrm{~h}$ 
following admission in the present study. Furthermore, the use of different experimental methods in the laboratory would also lead to inconsistent results $(8,59,60)$.

Univariant analysis in the present study concluded that the OR of $\log$ (NT-pro BNP) was 3.841, but following multivariant analysis, $\log$ (NT-pro BNP) was not categorized as an independent risk factor of UA when atherosclerotic plaques were detected by CCTA. In addition, the results of the present study demonstrated that there were no statistically significant differences between conventional risk factors of coronary heart disease among the three experimental groups. Therefore, it can be concluded that conventional risk factors have a limited value in predicting MACE.

It has been demonstrated that the pathogenesis of UA is not associated with the extent of lesions and the degree of luminal stenosis, but rather with plaque stability $(61,62)$. It was observed that a large amount of non-calcified plaque was unstable and vulnerable to rupture or erosion, and that the number of segments with non-calcified plaque was higher in patients with UA compared with the non-cardiac disease and SAP group. However, in the present study there were no statistically significant differences between the number of segments with non-calcified plaque among the three patient groups. It can be speculated that this was due to secondary thrombosis caused by plaque rupture or erosion that may have activated fibrinolytic systems in the body. Clots autolyzed subsequently. In coronary angiography, negative results were often obtained; clot autolysis was further confirmed by the HORIZONS-AMI Trial (63).

The limitations of the present study are as follows: The study was a single center study, and further studies would be required to acquire more accurate results; joint analysis with regular blood biomarkers was not performed; and the prognostic value of serum NT-pro BNP levels in patients with different compositions of atherosclerotic plaques requires further research.

In conclusion, the present study demonstrates that the expression level of NT-pro BNP is associated with coronary plaque, in particular calcified plaque, LM-LAD disease, and the severity of vessel stenosis in patients with UA. It can be suggested that NT-pro BNP is a marker of cardiac failure, and indicates the severity of coronary artery atherosclerotic disease. Although the expression level of NT-pro BNP was not an independent risk factor of UA, it may be helpful in risk stratification in patients with UA. Further research is required in order to explore the value of NT-pro BNP and plaque detection by CCTA in the risk stratification and prognosis of patients with UA.

\section{Acknowledgements}

The present study was supported by a grant from the National Natural Science Foundation of China (no. 81371547).

\section{References}

1. Han ZJ, Wu XD, Cheng JJ, Zhao SD, Gao MZ, Huang HY, Gu B, Ma P, Chen Y, Wang JH, et al: Diagnostic accuracy of natriuretic peptides for heart failure in patients with pleural effusion: A systematic review and updated meta-analysis. PLoS One 10: e0134376, 2015 .
2. Johnson KR and Olson KR: Responses of the trout cardiac natriuretic peptide system to manipulation of salt and water balance. Am J Physiol Regul Integr Comp Physiol 296: R1170-R1179, 2009.

3. Brutsaert DL: Cardiac dysfunction in heart failure: The cardiologist's love affair with time. Prog Cardiovasc Dis 49: 157-181, 2006.

4. Stępień-Wałek AM and Wożakowska-Kapłon B: The effect of left ventricle diastolic function on the secretion of B-type natriuretic peptide at rest and directly after exercise test in asymptomatic patients with diabetes or after myocardial infarction with preserved left ventricular systolic function. Kardiol Pol: Nov 12, 2015 (Epub ahead of print). doi: 10.5603/KP.a2015.0216.

5. Morita E, Yasue H, Yoshimura M, Ogawa H, Jougasaki M, Matsumura T, Mukoyama M and Nakao K: Increased plasma levels of brain natriuretic peptide in patients with acute myocardial infarction. Circulation 88: 82-91, 1993.

6. Ellulu MS, Patimah I, Khaza'ai H, Rahmat A, Abed Y and Ali F: Atherosclerotic cardiovascular disease: A review of initiators and protective factors. Inflammopharmacology 24: 1-10, 2016.

7. Lin E, Hashimoto B and Hwang W: Imaging of subclinical atherosclerosis: questions and answers. Curr Probl Diagn Radiol 40: 116-126, 2011.

8. Clerico A and Emdin M: Diagnostic accuracy and prognostic relevance of the measurement of cardiac natriuretic peptides: A review. Clin Chem 50: 33-50, 2004.

9. Doust JA, Glasziou PP, Pietrzak E and Dobson AJ: A systematic review of the diagnostic accuracy of natriuretic peptides for heart failure. Arch Intern Med 164: 1978-1984, 2004.

10. Roberts E, Ludman AJ, Dworzynski K, Al-Mohammad A, Cowie MR, McMurray JJ and Mant J; NICE Guideline Development Group for Acute Heart Failure: The diagnostic accuracy of the natriuretic peptides in heart failure: Systematic review and diagnostic meta-analysis in the acute care setting. BMJ 350: h910, 2015.

11. Clerico A, Fontana M, Zyw L, Passino C, Emdin M: Comparison of the diagnostic accuracy of brain natriuretic peptide (BNP) and the N-terminal part of the propeptide of BNP immunoassays in chronic and acute heart failure: A systematic review. Clin Chem 53: 813-822, 2007.

12. Szilveszter B, Celeng C and Maurovich-Horvat P: Plaque assessment by coronary CT. Int J Cardiovasc Imaging 32: 161-172, 2016.

13. Nakazato R, Otake H, Konishi A, Iwasaki M, Koo BK, Fukuya H, Shinke T, Hirata K, Leipsic J, Berman DS and Min JK: Atherosclerotic plaque characterization by $\mathrm{CT}$ angiography for identification of high-risk coronary artery lesions: A comparison to optical coherence tomography. Eur Heart J Cardiovasc Imaging 16: 373-379, 2015.

14. Hoffmann U, Truong QA, Fleg JL, Goehler A, Gazelle S, Wiviott S, Lee H, Udelson JE and Schoenfeld D: Design of the rule out myocardial ischemia/infarction using computer assisted tomography: A multicenter randomized comparative effectiveness trial of cardiac computed tomography versus alternative triage strategies in patients with acute chest pain in the emergency department. Am Heart J 163: 330-338, 2012.

15. Puchner SB, Ferencik M, Maurovich-Horvat P, Nakano M, Otsuka F, Kauczor HU, Virmani R, Hoffmann U and Schlett CL: Iterative image reconstruction algorithms in coronary CT angiography improve the detection of lipid-core plaque - a comparison with histology. Eur Radiol 25: 15-23, 2015.

16. Puchner SB, Liu T, Mayrhofer T, Truong QA, Lee H, Fleg JL, Nagurney JT, Udelson JE, Hoffmann U and Ferencik M: High-risk plaque detected on coronary CT angiography predicts acute coronary syndromes independent of significant stenosis in acute chest pain: Results from the ROMICAT-II trial. J Am Coll Cardiol 64: 684-692, 2014.

17. Zhou W, Ni Z, Yu Z, Shi B and Wang Q: Brain natriuretic peptide is related to carotid plaques and predicts atherosclerosis in pre-dialysis patients with chronic kidney disease. Eur J Intern Med 23: 539-544, 2012.

18. Hong YJ, Ahn Y, Sim DS, Yoon NS, Yoon HJ, Kim KH, Park HW, Kim JH, Jeong MH, Cho JG, et al: Relation between N-terminal pro-B-type natriuretic peptide and coronary plaque components in patients with acute coronary syndrome: Virtual histology-intravascular ultrasound analysis. Coron Artery Dis 20: 518-524, 2009.

19. Peng XL, Lin ZP, Zhang RK and Zhang ZW: B-type natriuretic peptides and subclinical target organ damage in essential hypertensive patients. Nan Fang Yi Ke Da Xue Xue Bao 30: 2347-2350, 2010 (In Chinese). 
20. Altintas S, Cardinaels EP, Versteylen MO, Joosen IA, Seifert M Wildberger JE, Crijns HJ, Nelemans PJ, Van Dieijen-Visser MP, Mingels AM, et al: Unstable coronary plaque characteristics are associated with high-sensitivity cardiac troponin $\mathrm{T}$ and $\mathrm{N}$-terminal pro-brain natriuretic peptide. J Cardiovasc Comput Tomogr 10: 82-88, 2016.

21. Amsterdam EA, Wenger NK, Brindis RG, Casey DE Jr, Ganiats TG, Holmes DR Jr, Jaffe AS, Jneid H, Kelly RF, Kontos MC, et al; American College of Cardiology; American Heart Association Task Force on Practice Guidelines; Society for Cardiovascular Angiography and Interventions; Society of Thoracic Surgeons; American Association for Clinical Chemistry: 2014 AHA/ACC Guideline for the Management of Patients with Non-ST-Elevation Acute Coronary Syndromes: A report of the American College of Cardiology/American Heart Association Task Force on Practice Guidelines. J Am Coll Cardiol 64: e139-e228, 2014.

22. Taylor AJ, Cerqueira M, Hodgson JM, Mark D, Min J, O'Gara P, Rubin GD, Kramer CM, Berman D, Brown A, et al; American College of Cardiology Foundation Appropriate Use Criteria Task Force; Society of Cardiovascular Computed Tomography; American College of Radiology; American Heart Association; American Society of Echocardiography; American Society of Nuclear Cardiology; North American Society for Cardiovascular Imaging; Society for Cardiovascular Angiography and Interventions; Society for Cardiovascular Magnetic Resonance: ACCF/SCCT/ACR/AHA/ASE/ASNC/NASCI/SCAI/

SCMR 2010 appropriate use criteria for cardiac computed tomography. A report of the American College of Cardiology Foundation Appropriate Use Criteria Task Force, the Society of Cardiovascular Computed Tomography, the American College of Radiology, the American Heart Association, the American Society of Echocardiography, the American Society of Nuclear Cardiology, the North American Society for Cardiovascular Imaging, the Society for Cardiovascular Angiography and Interventions, and the Society for Cardiovascular Magnetic Resonance. J Am Coll Cardiol 56: 1864-1894, 2010.

23. Abbara S, Arbab-Zadeh A, Callister TQ, Desai MY, Mamuya W, Thomson L and Weigold WG: SCCT guidelines for performance of coronary computed tomographic angiography: A report of the Society of Cardiovascular Computed Tomography Guidelines Committee. J Cardiovas Comput Tomogr 3: 190-204, 2009.

24. Raff GL, Abidov A, Achenbach S, Berman DS, Boxt LM, Budoff MJ, Cheng V, DeFrance T, Hellinger JC, Karlsberg RP; Society of Cardiovascular Computed Tomography: SCCT guidelines for the interpretation and reporting of coronary computed tomographic angiography. J Cardiovasc Comput Tomogr 3: 122-136, 2009

25. Austen WG, Edwards JE, Frye RL, Gensini GG, Gott VL, Griffith LS, McGoon DC, Murphy ML and Roe BB: A reporting system on patients evaluated for coronary artery disease. Report of the Ad Hoc Committee for Grading of Coronary Artery Disease, Council on Cardiovascular Surgery, American Heart Association. Circulation 51 (Suppl): 5-40, 1975.

26. Agatston AS, Janowitz WR, Hildner FJ, Zusmer NR, Viamonte M Jr and Detrano R: Quantification of coronary artery calcium using ultrafast computed tomography. J Am Coll Cardiol 15: 827-832, 1990.

27. Luscher TF: Substrates of acute coronary syndromes: new insights into plaque rupture and erosion. Eur Heart J 36: 1347-1349, 2015.

28. Turer AT, Lewis GD, O'Sullivan JF, Elmariah S, Mega JL, Addo TA, Sabatine MS, de Lemos JA and Gerszten RE: Increases in myocardial workload induced by rapid atrial pacing trigger alterations in global metabolism. PLoS One 9: e99058, 2014.

29. Sabatine MS, Liu E, Morrow DA, Heller E, McCarroll R, Wiegand R, Berriz GF, Roth FP and Gerszten RE: Metabolomic identification of novel biomarkers of myocardial ischemia. Circulation 112: 3868-3875, 2005

30. Turer AT, Stevens RD, Bain JR, Muehlbauer MJ, van der Westhuizen J, Mathew JP, Schwinn DA, Glower DD, Newgard CB and Podgoreanu MV: Metabolomic profiling reveals distinct patterns of myocardial substrate use in humans with coronary artery disease or left ventricular dysfunction during surgical ischemia/reperfusion. Circulation 119: 1736-1746, 2009.

31. Lewis GD, Wei R, Liu E, Yang E, Shi X, Martinovic M, Farrell L, Asnani A, Cyrille M, Ramanathan A, et al: Metabolite profiling of blood from individuals undergoing planned myocardial infarction reveals early markers of myocardial injury. J Clin Invest 118: 3503-3512, 2008
32. Scardovi AB; Associazione Nazionale Medici Cardiologi Ospedalieri; Società Italiana di Cardiologia Pediatrica; Società Italiana di Nefrologia Pediatrica; Società Italiana dell'Ipertensione Arteriosa; Società Italiana di Pediatria: Clinical applications of brain natriuretic peptide testing. Ital Heart J Suppl 5: 343-356, 2004 (In Italian).

33. Meune C, Fulla Y, Martins E, Bergmann JF and Devaux JY: B-type natriuretic peptide for the diagnostic and prognostic assessment in cardiology. Its interest and perspectives of application. Presse Med 32: 181-185, 2003 (In French).

34. Clerico A, Recchia FA, Passino C and Emdin M: Cardiac endocrine function is an essential component of the homeostatic regulation network: Physiological and clinical implications. Am J Physiology Heart Circ Physiol 290: H17-H29, 2006.

35. Mazzone M, Forte P, Portale G, Mancini F, Ursella S, La Sala M, Testa A, Covino M, Pignataro G and Gentiloni Silveri N: Brain natriuretic peptide and acute coronary syndrome. Minerva Med 96: 11-18, 2005.

36. McCullough PA, Peacock WF, O'Neil B, de Lemos JA, Lepor NE and Berkowitz R: An evidence-based algorithm for the use of B-type natriuretic testing in acute coronary syndromes. Rev Cardiovasc Med 11 Suppl 2: S51-S65, 2010.

37. Sun C, Zhi J, Bai X, Li X and Xia H: Comparison of the efficacy of recombinant human brain natriuretic peptide with saline hydration in preventing contrast-induced nephropathy in patients undergoing coronary angiography with or without concomitant percutaneous coronary intervention. Int J Clin Exp Med 8: 14166-14172, 2015 .

38. Zürcher S, Honegger U, Wagener M, Lee G, Stallone F, Marxer T, Puelacher C, Schumacher C, Sou SM, Twerenbold R, et al: Delayed release of brain natriuretic peptide to identify myocardial ischaemia. Eur J Clin Invest 45: $1175-1183,2015$.

39. Sun $\mathrm{Z}$ and $\mathrm{Xu} \mathrm{L}$ : Coronary $\mathrm{CT}$ angiography in the quantitative assessment of coronary plaques. Biomed Res Int 2014: 346380, 2014.

40. Obaid DR, Calvert PA, Gopalan D, Parker RA, West NE, Goddard M, Rudd JH and Bennett MR: Dual-energy computed tomography imaging to determine atherosclerotic plaque composition: A prospective study with tissue validation. J Cardiovasc Comput Tomogr 8: 230-237, 2014.

41. Radwan H, Selem A and Ghazal K: Value of N-terminal pro brain natriuretic peptide in predicting prognosis and severity of coronary artery disease in acute coronary syndrome. J Saudi Heart Assoc 26: 192-198, 2014.

42. James SK, Lindahl B, Siegbahn A, Stridsberg M, Venge P, Armstrong P, Barnathan ES, Califf R, Topol EJ, Simoons ML and Wallentin L: N-terminal pro-brain natriuretic peptide and other risk markers for the separate prediction of mortality and subsequent myocardial infarction in patients with unstable coronary artery disease: A Global Utilization of Strategies To Open occluded arteries (GUSTO)-IV substudy. Circulation 108: 275-281, 2003

43. Hong YJ, Ahn Y, Sim DS, Yoon NS, Yoon HJ, Kim KH, Park HW, Kim JH, Jeong MH, Cho JG, et al: Relation between $\mathrm{N}$-terminal pro-B-type natriuretic peptide and coronary plaque components in patients with acute coronary syndrome: virtual histology-intravascular ultrasound analysis. Coron Artery Dis 20: 518-524, 2009.

44. Beaufrere H, Nevarez JG, Holder K, Pariaut R, Tully TN and Wakamatsu N: Characterization and classification of psittacine atherosclerotic lesions by histopathology, digital image analysis, transmission and scanning electron microscopy. Avian Pathol 40: 531-544, 2011.

45. Stary HC, Chandler AB, Dinsmore RE, Fuster V, Glagov S, Insull W Jr, Rosenfeld ME, Schwartz CJ, Wagner WD and Wissler RW: A definition of advanced types of atherosclerotic lesions and a histological classification of atherosclerosis. A report from the Committee on Vascular Lesions of the Council on Arteriosclerosis, American Heart Association. Circulation 92: 1355-1374, 1995.

46. Saremi F and Achenbach S: Coronary plaque characterization using CT. AJR Am J Roentgenol 204: W249-W260, 2015.

47. Salama RH, El-Moniem AE, El-Hefney N and Samor T: N-Terminal PRO-BNP in acute coronary syndrome patients with ST elevation versus non ST elevation in Qassim region of Saudi Arabia. Int J Health Sci (Qassim) 5: 136-145, 2011.

48. Maurovich-Horvat P, Ferencik M, Voros S, Merkely B and Hoffmann U: Comprehensive plaque assessment by coronary CT angiography. Nat Rev Cardiol 11: 390-402, 2014. 
49. Min JK, Lin FY, Dunning AM, Delago A, Egan J, Shaw LJ, Berman DS and Callister TQ: Incremental prognostic significance of left ventricular dysfunction to coronary artery disease detection by 64 -detector row coronary computed tomographic angiography for the prediction of all-cause mortality: results from a two-centre study of 5330 patients. Eur Heart J 31: 1212-1219, 2010.

50. Sozzi FB, Civaia F, Rossi P, Robillon JF, Rusek S, Berthier F, Bourlon F, Iacuzio L, Dreyfus G and Dor V: Long-term follow-up of patients with first-time chest pain having 64-slice computed tomography. Am J Cardiol 107: 516-521, 2011.

51. Shmilovich H, Cheng VY, Tamarappoo BK, Dey D, Nakazato R, Gransar H, Thomson LE, Hayes SW, Friedman JD Germano $\mathrm{G}$, et al: Vulnerable plaque features on coronary CT angiography as markers of inducible regional myocardial hypoperfusion from severe coronary artery stenoses. Atherosclerosis 219 : 588-595, 2011.

52. Schlett CL, Nance JW, Jr., Schoepf UJ, O'Brien TX, Ebersberger U, Headden GF, Hoffman U and Bamberg F: Differences in coronary artery disease by CT angiography between patients developing unstable angina pectoris vs. major adverse cardiac events. Eur J Radiol 83: 1113-1119, 2014.

53. Chow BJ, Wells GA, Chen L, Yam Y, Galiwango P, Abraham A, Sheth T, Dennie C, Beanlands RS and Ruddy TD: Prognostic value of 64-slice cardiac computed tomography severity of coronary artery disease, coronary atherosclerosis, and left ventricular ejection fraction. J Am Coll Cardiol 55: 1017-1028, 2010.

54. Palazzuoli A, Gennari L, Calabria P, Quatrini I, Vecchiato L, De Paola V, Campagna MS, Palazzuoli V and Nuti R: Relation of plasma brain natriuretic peptide levels in non-ST-elevation coronary disease and preserved systolic function to number of narrowed coronary arteries. Am J Cardiol 96: 1705-1710, 2005.

55. Sadanandan S, Cannon CP, Chekuri K, Murphy SA, Dibattiste PM, Morrow DA, de Lemos JA, Braunwald E and Gibson CM: Association of elevated B-type natriuretic peptide levels with angiographic findings among patients with unstable angina and non-ST-segment elevation myocardial infarction. J Am Coll Cardiol 44: 564-568, 2004.
56. Weber M, Dill T, Arnold R, Rau M, Ekinci O, Müller KD, Berkovitsch A, Mitrovic V and Hamm C: N-terminal B-type natriuretic peptide predicts extent of coronary artery disease and ischemia in patients with stable angina pectoris. Am Heart J 148: 612-620, 2004

57. Liu B, Fu Q, Yan QN, Jin W, Tao DP, Hua JH and Li ZL: Value of biochemical marker detection in risk stratification in patients with acute coronary syndrome. Nan Fang Yi Ke Da Xue Xue Bao 30: 1015-1019, 2010.

58. Lewandrowski K, Chen A and Januzzi J: Cardiac markers for myocardial infarction. A brief review. Am J Clin Pathology 118 Suppl: S93-S99, 2002.

59. Clerico A, Prontera C, Emdin M, Passino C, Storti S, Poletti R, Zyw L and Zucchelli GC: Analytical performance and diagnostic accuracy of immunometric assays for the measurement of plasma B-type natriuretic peptide (BNP) and N-terminal proBNP. Clin Chem 51: 445-447, 2005.

60. Apple FS, Panteghini M, Ravkilde J, Mair J, Wu AH, Tate J, Pagani F, Christenson RH and Jaffe AS: Committee on Standardization of Markers of Cardiac Damage of the IFCC: Quality specifications for B-type natriuretic peptide assays. Clin Chem 51: 486-493, 2005.

61. Dey D, Achenbach S, Schuhbaeck A, Pflederer T, Nakazato R, Slomka PJ, Berman DS and Marwan M: Comparison of quantitative atherosclerotic plaque burden from coronary CT angiography in patients with first acute coronary syndrome and stable coronary artery disease. J Cardiovasc Comput Tomogr 8: 368-374.

62. Toutouzas K, Stathogiannis K, Synetos A, Karanasos A and Stefanadis C: Vulnerable atherosclerotic plaque: From the basic research laboratory to the clinic. Cardiology 123: 248-253, 2012.

63. Larsen AI, Nilsen DW, Yu J, Mehran R, Nikolsky E, Lansky AJ, Caixeta A, Parise H, Fahy M, Cristea E, et al: Long-term prognosis of patients presenting with ST-segment elevation myocardial infarction with no significant coronary artery disease (from the HORIZONS-AMI trial). Am J Cardiol 111: 643-648, 2013. 